\title{
DRIVER PSYCHOLOGICAL TYPES AND CAR FOLLOWING: IS THERE A CORRELATION? RESULTS OF A PILOT STUDY
}

\author{
Mark Brackstone \\ Transportation Research Group, \\ Dept. of Civil and Environmental Engineering, \\ University of Southampton, \\ Highfield, Southampton, SO17 1BJ, U.K. \\ E-mail: mab6@soton.ac.uk
}

\begin{abstract}
Summary: Many studies have attempted to measure driver behaviour or to classify drivers' attributes according to questionnaires based on psychological indicators. Although such studies have met with success, for example, correlating behavioural types with accident risk, few attempts have been made to correlate these attributes with direct, dynamically measurable quantities such as desired following distance or its responsiveness to speed changes. In this paper we will examine whether such a correlation is possible by examining results from a pilot study using an instrumented vehicle and a group of eleven subjects. In particular we will focus on how following distances are correlated to the Sensation Seeking and Internality-Externality Scales
\end{abstract}

\section{BACKGROUND}

Two areas of work that have seen extensive examination in the last decade are the characterization of drivers according to a number of social/psychological measures, and the examination of the dynamic behaviour of drivers, for example the speed dependant following distance that drivers adopt behind each other while driving. Although many have speculated that 'aggressive' or 'passive' drivers will act differently in such circumstances, and indeed have formulated rule of thumb relationships, little work has been done to examine the applicability of such measures to describing dynamic behaviour.

Certainly, there has been a wide range of work performed on attempting to classify drivers according to differing behaviour types, and a certain amount of success can be had in linking such measures as risk taking with accident risk (see Wasielewski, 1984; Elander et al., 1993; Parker et al., 1995; and Ulleberg, 2002 for a range of studies) or with subjective estimation of congestion (Stokols et al., 1978). Direct correlation with real driving variables is, however, quite rare. Roadside measurements of spot speeds and headways related to driver characteristics through licence plate records undertaken by Evans and Wasielewski (1983) demonstrated higher time headways for older drivers (approximately $1.2 \mathrm{sec}$ for drivers under 30 and around $0.2 \mathrm{sec}$. more for drivers over 50), and showed that drivers with more recorded accidents or violation 'points' typically were likely to be found driving with lower headways. Unfortunately no information is given as to how these relationships vary with speed, and no examination is made of how representative each measurement is of each driver's true behaviour. Alternatively, using a low-fidelity driving simulator, Matthews et al. (1993) has demonstrated that mean open-road speed could be related to age and sex, with distance variability in a following task linked to age; in an instrumented vehicle study, Boyce et al. (2002) has shown that older drivers are more likely 
to drive at longer distances. There is, however, little information on how driver characteristics or personality types affect dynamic behaviour measured on the road, and it is the intent of this paper to report on a pilot study undertaken to determine if car-following behaviour can be predicted by a number of commonly used and/or simple measures.

\section{DATA COLLECTION AND ANALYSIS}

Data used in this study has been collected from a series of instrumented vehicle experiments performed using two groups of drivers. The first, group A ( 5 subjects all male), took part in carfollowing experiments during 1997/98, primarily in congestion-free traffic. The second, group B (6 subjects, 5 male 1 female) participated in similar, although more detailed and extensive, trials in 2000/01 in higher flow conditions. The following experiments have all involved subjects driving the test vehicle (a 2-litre estate car, Brackstone et al., 1999) on 3-lane motorways in the U.K. (the M3 and the M27 near the city of Southampton), with measurements being taken of driver speed and distance to the preceding vehicle using an automotive radar unit (Brackstone et al., 2002).

\section{Measures of Following Distance}

For each driver a number of following 'spirals' have been extracted describing the modulation of following distance over time according to relative speed. The data has been filtered to remove all points where the acceleration of the test driver exceeded $0.6 \mathrm{~m} / \mathrm{s}^{2}$ in magnitude (a level below which, it has been demonstrated, drivers are comfortable with their distance, Sultan, 2000). An average of the remaining points have been taken across four sets of 'bins' to provide an indication of average headway at 10, 30, 50 and $70 \mathrm{mph}$ (bin width 4mph, AT10, AT30, AT50 and AT70) along with the spread of values observed, denoted by the standard deviations at these speeds (Std10, Std30 etc.).

\section{Independent Variables}

The indicators of driver personality/experience used for this study have been:

- Age,

- Approximate mileage driven per year,

- A subjective rating of each subject's Passivity/Aggressiveness on a five-valued scale $(\mathrm{P} / \mathrm{A})$,

- A subjective rating of each subject's Driving Speed (Slow to Fast) again on a five-valued scale $(\mathrm{S} / \mathrm{F})$,

- DE and DI (Driver Externality and Driver Internality ratings) measuring each driver's feelings regarding locus of control and responsibility (Montag and Comrey, 1987), and,

- SSSV (Sensation Seeking Scale V) describing each driver's attitude towards differing types of sensation seeking (Zuckerman, 1994, split into 4 sub-scales: Thrill and Adventure Seeking, Experience Seeking, Boredom Susceptibility, and Disinhibition, for a thorough review of its use in driver behaviour research see Jonah, 1997). 


\section{Correlations}

Results from a bi-variate 2-tailed correlation analysis are given in Table 1 (measures vs dependant variables), and correlation coefficients of significant interactions for measuresindependent variables given in Table 2.

Table 1. Correlation significance between measures and dependent variables

\begin{tabular}{l|l|l|l|l|l|l|l} 
& DI & DE & SSSV & P/A & S/F & Age & Mileage \\
\hline AT10 & 0.187 & $\mathbf{0 . 0 3 0}^{*}$ & $\mathbf{0 . 0 2 8}^{*}$ & 0.862 & 0.592 & 0.180 & 0.710 \\
Std10 & 0.314 & 0.065 & 0.075 & 0.911 & 0.780 & 0.138 & 0.515 \\
AT30 & 0.243 & $\mathbf{0 . 0 0 2}^{* *}$ & $\mathbf{0 . 0 0 2}^{* *}$ & 0.859 & 0.468 & 0.251 & 0.568 \\
Std30 & 0.216 & 0.099 & 0.111 & 0.656 & 0.584 & 0.087 & 0.106 \\
AT50 & 0.597 & 0.656 & 0.983 & $\mathbf{0 . 0 4 6}$ & 0.158 & 0.853 & 0.182 \\
Std50 & 0.199 & 0.860 & 0.790 & 0.879 & 0.900 & $\mathbf{0 . 0 1 1}^{*}$ & 0.449 \\
AT70 & 0.492 & 0.788 & 0.935 & 0.076 & 0.062 & 0.174 & 0.224 \\
Std70 & 0.646 & 0.318 & 0.563 & 0.953 & 0.359 & 0.497 & 0.415
\end{tabular}

Significant correlations given in Bold, ${ }^{*}$ significant to $\mathrm{p}<0.05,{ }^{* *}$ significant to $\mathrm{p}<0.01$. Italics, $\mathrm{p}<0.1$.

Table 2. Key correlation coefficients

\begin{tabular}{l|l|l|l|l|l} 
& DE & SSSV & P/A & S/F & Age \\
\hline AT10 & $\mathbf{0 . 8 5 5 *}$ & $\mathbf{- 0 . 8 6 1 *}$ & 0.092 & 0.259 & 0.630 \\
Std10 & 0.784 & -0.767 & -0.059 & 0.148 & 0.679 \\
AT30 & $\mathbf{0 . 9 6 6 * *}_{\text {Std30 }}^{0.731}$ & $\mathbf{- 0 . 9 6 6 * *}$ & 0.094 & 0.372 & 0.557 \\
AT50 & 0.152 & -0.714 & -0.233 & 0.285 & 0.749 \\
Std50 & 0.860 & 0.007 & $-\mathbf{0 . 6 1 1 *}$ & -0.456 & 0.063 \\
AT70 & 0.788 & 0.091 & 0.052 & 0.043 & $\mathbf{0 . 7 3 1 *}$ \\
Std70 & 0.318 & -0.030 & -0.585 & -0.608 & 0.467 \\
& & 0.209 & 0.021 & -0.325 & 0.244
\end{tabular}

It is clear that there is a degree of correlation present between DE, SSSV and low speed behaviour (30 mph or less), mostly in terms of the average distance but to a certain extent with the standard deviation too. This would seem to demonstrate that those with higher scores on the DE scale would have higher following distances (and deviations) while those with higher SSSV scores would have lower. At the higher speed categories, however, these measures would not seem to be valid predictors with the emphasis seeming to switch more (for the average following distance at least) to the subjects' subjective scores of aggressiveness, speed, etc., with the drivers on the more aggressive and faster end of the scales exhibiting closer behaviours.

It is also interesting to examine the correlations between the measures (Table 3 below), where we find an unsurprising link between the DE and DI scores with a Pearson correlation coefficient of -0.69 (the two scores are in essence measures of opposing characteristics), P/A and S/F (Pearson. Coeff 0.634), and perhaps most interestingly DE and SSS (Pearson co-eff. -0.618). 
Table 3. Correlation significance between measures

\begin{tabular}{l|l|l|l|l|l|l} 
& DE & SSSV & P/A & S/F & Age & Mileage \\
\hline DI & $\mathbf{0 . 0 3 4}$ & 0.904 & 0.534 & 0.369 & 0.293 & 0.809 \\
DE & & $\mathbf{0 . 0 4 3 *}$ & 0.248 & 0.324 & 0.773 & 0.974 \\
SSSV & - & & 0.453 & 0.650 & 0.712 & 0.440 \\
P/A & - & - & & $\mathbf{0 . 0 3 6 *}$ & 0.976 & 0.260 \\
S/F & - & - & - & & 0.693 & 0.590 \\
Age & - & - & - & - & & 0.764
\end{tabular}

${ }^{*}$ Correlation significant to $\mathrm{p}<0.05,{ }^{* *}$ correlation significant to $\mathrm{p}<0.01$.

\section{CONCLUSIONS}

Although of limited scope, our work has served to present a number of interesting possibilities, in particular that following behaviour may be split into two phases somewhere between 30 and $50 \mathrm{mph}$, behaviour in the lower end of which may be parameterized through the use of simple questionnaires. The upper phase, however, is more accurately described by drivers' own subjective opinion of their behaviour. For lower speed there would seem to be an inverse relationship between SSSV and following distance - arguably the sensation seekers are seeking more excitement and risk by driving closer. In previous studies the SSSV scale has been shown to be correlated to self-reported risky driving behaviour (Jonah et al., 2001) but not to be a significant indicator of self-reported tailgating, a finding borne out for higher speeds in our analysis but not for lower, while Heino et al. (1996) has demonstrated a clear difference $(\mathrm{p}=0.01)$ between sensation seekers and avoiders, driving with average headways of 1.2 and $1.8 \mathrm{sec}$ respectively at $110 \mathrm{kph}(36.1 \mathrm{vs} 55.6 \mathrm{~m})$, a finding not confirmed in our study and potentially at odds with those of Jonah (2001).

Relating higher DE scores to longer distances, however, would seem to be a contradiction as "externality is related to a lack of caution and a failure to take precautionary steps" (Montag and Comrey, 1987, p. 339). One can argue that this would mean a 'lack of caution' manifested as closer distances, however this is not strictly correct. For instance, as those rating highly on the internal (DI) scale have been demonstrated to be "highly motivated and perform better," maybe an inverse correlation should be expected with DI and not DE, with such individuals driving closer because the feel that they can due to their increased subjective levels of capability.

Clearly our findings should be viewed with caution and sample size aside, several criticisms are possible, for example we have not accounted for the variability of driver behaviour from day to day and how effects of, for instance, driver stressors may affect distance (Gulian et al., 1989). Similarly our analysis has assumed a very simple approach and has not examined potential nonlinear dependencies in our data. This line of investigation however is worth pursuing as the differences between subjective and objective driver behaviour is still not well understood, and parameterization of objective behaviour is still in its infancy. 


\section{ACKNOWLEDGEMENTS}

Work reported in this paper has been funded by the EPSRC in the U.K. (Contract No. GR/M94410). Thanks are also due to Ben Waterson for his many helpful comments during the preparation of this paper.

\section{REFERENCES}

Boyce, T. E. and Geller, E.S. (2002). An Instrumented Vehicle Assessment of Problem Behaviour and Driving Style: Do Younger Drivers Really Take More Risks? Acc. Analy. \& Prev., 34, 51-64.

Brackstone, M., McDonald, M. and Sultan, B. (1999). Dynamic Behavioural Data Collection Using an Instrumented Vehicle. Transpn. Res. Rec., 1689, 9-17.

Brackstone, M., Waterson, B. and McDonald, M. (2002). Determinants of Following Distance. Submitted to Human Factors.

Elander, J., West, R., and French, D. (1993). Behavioural Correlates of Individual Differences in Road-Traffic Crash Risk: An Examination of Methods and Findings. Psychological Bulletin, 113(2), 270-294.

Evans, L., and Wasielewski, P. (1983). Risky Driving Related to Driver and Vehicle Characteristics. Accid. Analy. \& Prev., 15(2), 121-136.

Gulian, E., Matthews, G., Glendon, A. I., Davies, D. R. and Debney, L. M. (1989). Dimensions of Driver Stress. Ergonomics, 32(6), 585-602.

Heino, A., van der Molen, H. and Wilde, G. (1996). Differences in Risk Experience between Sensation Avoiders and Sensation Seekers. Person. Individ. Diff. 20(1), 71-79.

Jonah, B. A. (1997). Sensation Seeking and Risky Driving: A Review and Synthesis of the Literature. Analy. \& Prev., 29, 651-665.

Jonah, B. A., Thiessen, R and Au-Yeung, E. (2001). Sensation Seeking, Risky Driving and Behavioural Adaptation. Acc. Analy. \& Prev., 33, 679-684.

Matthews, G., Dorn, L., Hoyes, T. and Glendon, A. et al. (1993). Driver Stress and Simulated Driving: Studies of Risk Taking and Attention. Proc. of Behavioural Research in Road Safety III. University of Kent, 22-23 ${ }^{\text {rd }}$ Sept. 1993. TRL, Crowthorne, Berks., U.K.

Montag, I. and Comrey, A. L. (1987). Internality and Externality as Correlates of Involvement in Fatal Driving Accidents. Jnl. of Applied Psychology, 72(3), 339-343.

Parker, D., Reason, J. T., Manstead, A. S. R. and Stradling, S. G. (1995). Driving Errors, Driving Violations and Accident Involvement. Ergonomics, 38(5), 1036-1048.

Stokols, D., Novaco, R. W. Stokols, J., and Campbell, J. (1978). Traffic Congestion, Type A Behaviour, and Stress. Jnl. of Applied Psychology, 63(4), 467-480.

Sultan, B. (2000). The Study of Motorway Operation using a Microscopic Simulation Model. Doctoral Thesis, Dept. of Civil and Environ. Eng., University of Southampton, U.K.

Ulleberg, P. (2002). Personality Subtypes of Young Drivers. Relationship to Risk-taking Preferences, Accident Involvement, and Response to a Traffic Safety Campaign. Transp. Res. F, 4, 279-297.

Wasielewski, P. (1984). Speed as a Measure of Driver Risk: Observed Speeds Versus Driver and Vehicle Characteristics. Accid. Analy. \& Prev., 16(2), 89-103. 
PROCEEDINGS of the Second International Driving Symposium on Human Factors in Driver Assessment, Training and Vehicle Design

Zuckerman, M. (1994). Behavioural Expressions and Biosocial Bases of Sensation Seeking. New York: Cambridge University Press. 